\title{
CONHECENDO OS/AS PROFISSIONAIS DE CRECHE DO MUNICÍPIO DE DESCALVAD0*
}

\author{
GETTING TO KNOW THE PROFESSIONALS OF DAY CARE CENTERS IN THE \\ CITY OF DESCALVADO/SP
}

\section{CONOCIENDO LOS/LAS PROFESIONALES DE LA GUARDERÍA INFANTIL DEL MUNICIPIO DE DESCALVADO}

\begin{abstract}
Maria Beatriz Jacomini** Aline Sommerhalder ***

Resumo: Este texto decorre de uma pesquisa de iniciação científica concluída e realizada a partir de uma ação de formação continuada de professores e gestores de educação infantil no município de Descalvado/SP, realizada por meio da atividade de extensão intitulada Formação de Professores de Educação Básica: uma parceria colaborativa entre escola e universidade. Partindo da problemática “Quem são os/as profissionais docentes das Creches municipais de Descalvado/SP?”, a pesquisa teve como objetivo levantar e conhecer a trajetória profissional e características de um grupo de profissionais docentes de creches do município de Descalvado/SP, participantes de atividade extensionista. A pesquisa teve caráter qualitativo e os dados foram coletados por meio de aplicação de questionário em 29 profissionais de Educação Infantil. Os resultados evidenciaram, dentre outros pontos, que o grupo em questão em sua maioria é mulher (28 profissionais), possui experiência consolidada em docência, em vários níveis de ensino, incluindo a etapa da Educação Infantil e que a grande maioria possui formação superior em Pedagogia. O estudo evidenciou ainda que a maioria das/dos colaboradoras/res desta pesquisa participou de cursos de formação contínua nos últimos cinco anos e para muitos/as a escolha pela atuação em creches decorreu de necessidade de trabalhar e falta de oportunidade profissional.
\end{abstract}

Palavras-Chave: Creche. Docente. Profissionais de Educação Infantil. Rede Municipal de Ensino.

\begin{abstract}
This study results from undergraduate survey made from an action in Continuing Education for teachers and administrators of Early Childhood Education in Descalvado/SP, accomplished through an extension activity project titled Basic Education Teachers Training: a collaborative partnership between the school and the university. The research question was: Who are the teachers of Day Care schools in the city of Descalvado/SP? The aim was to meet the professional development and characteristics of a group of kindergarten teachers in Descalvado/SP, who are participants of an extension activity project. This is a qualitative study and the data were collected through a questionnaire on 29 Early Childhood
\end{abstract}

\footnotetext{
*Pesquisa financiada pelo programa PADRD - Programa de Apoio ao Docente Recém Doutor/PUICT/Universidade Federal de São Carlos/São Carlos/SP.

**Universidade Federal de São Carlos - UFSCar. biajacomini@gmail.com

***Universidade Federal de São Carlos - UFSCar. alinesommer@ufscar.br
} 
professionals. The results showed, among other points, that the group is mostly formed by women (28 professionals), the people have consolidated experience in teaching in various levels of education, including the stage of Early Childhood education and the majority holds a degree in Education. The study also showed that most of collaborators participated in Continuing Education courses in the past five years and many of them did it as a choice for acting in day care schools, a result from the need of working and lack of professional opportunity.

Keywords: Day Care schools. Early Childhood Education. City Schools.

Resumen: Este texto se da de una pesquisa de iniciación científica concluida y realizada a partir de una acción de formación continuada de profesores y gestores de educación infantil en el municipio de Descalvado/SP, realizada por medio de la actividad de extensión intitulada: Formación de Profesores de Educación Básica: una asociación colaborativa entre escuela y universidad. Partiendo de la problemática “Quién son los/las profesionales docentes de las guarderías infantiles municipales de Descalvado/SP?”, la pesquisa tuvo como objetivo levantar y conocer la trayectoria profesional y características de un grupo de profesionales docentes de las guarderías infantiles del municipio de Descalvado/SP, participantes de la actividad extensionista. La pesquisa tuvo carácter cualitativo y los dados fueron colectados por medio de aplicaciones de cuestionario en 29 profesionales de la Educación Infantil. Los resultados evidenciaron, entre otros puntos, que el grupo en cuestión en su mayoría es mujer (28 profesionales), posee experiencia consolidada de docencia, en varios niveles de enseñanza, incluyendo la etapa de la Educación Infantil y que la gran mayoría posee formación superior en Pedagogía. El estudio evidenció aun que la mayoría de las/ los colaboradoras/res de esta pesquisa participó de cursos de formación continua en los últimos cinco años y para muchos/as la elección por la actuación en guarderías infantiles recurrió de la necesidad de trabajar y falta de oportunidad profesional.

Palabras-Clave: Guardería infantil. Docente. Profesionales de Educación Infantil. Red Municipal de Enseñanza.

\section{Introdução}

A educação infantil como primeira etapa da Educação Básica define-se pelo trabalho compartilhado entre família e escola nas práticas de educar e cuidar das crianças de forma indissociável. Para a realização das práticas docentes nesta etapa educativa, é fundamental considerar as especificidades da linguagem das crianças, das interações, do brinquedo e a organização do tempo e espaço nas instituições de Educação Infantil.

Um breve olhar para o contexto histórico da Educação Infantil nos possibilita perceber que esta etapa vivenciou diversas fases interligadas e, às vezes, simultâneas e conjuntas: a filantrópica, a higiênico-sanitária, a assistencial e a educacional.

De acordo com Marquez (2006), no Império (1822-1889), a perspectiva filantrópica (assistência/caridade) existia, e a perspectiva higienista também já se fazia presente, uma vez que não bastava à criança ser cuidada, era necessário que as crianças tivessem condições de ter qualidade de vida para sobreviver. O higienismo surgiu em razão de altos índices de mortalidade infantil, das condições precárias 
de saúde dos adultos e da disseminação para a sociedade de novos conhecimentos e técnicas científicas.

Na Primeira República (1889-1929), as perspectivas filantrópica e higienista caminharam juntas, porém se instalou a educação pré-escolar para os filhos das camadas médias e superiores da sociedade, enquanto que, para os filhos de ex-escravos, operários e trabalhadores em geral, instalaram-se entidades do âmbito da assistência social e da saúde pública (MARQUEZ, 2006). As creches nasceram no final do século XIX com um caráter assistencialista, pois, além de terem um caráter de assistência à criança, eram vistas também como opção para mulheres trabalhadoras deixarem seus filhos enquanto trabalhavam. Estas creches, entretanto, ainda eram vistas como um local que apenas cuidavam de crianças abandonadas e de classes sociais menos favorecidas.

Ressalta Kuhlmann Junior (1998) que a creche não era defendida por todos, uma vez que promovia conflitos, principalmente em relação à defesa social da atribuição de responsabilidade primordial à mãe na educação da pequena infância.

Foi possível constatar duas formas de caracterização e das funções nos diversos tipos de ações realizadas em creches e pré-escolas durante as últimas décadas do século $\mathrm{XX}$, com mais ênfase até o final da década de 1980. Havia instituições que realizavam um trabalho compreendido por muitos como “educativo” (que possuíam caráter pedagógico), e outras que realizavam um trabalho denominado "assistencialista” ( pois estavam relacionadas mais estritamente às ações de cuidado das crianças) (CERISARA, 1999). No entanto, destaca esta autora que esta cisão não deve ser feita entre estas duas funções (educativo e assistencial), pois tanto creches quanto pré-escolas realizavam ações de caráter educativo, ou seja, as primeiras realizavam uma proposta de educação para crianças pobres, e a segunda uma proposta educacional para as crianças economicamente mais favorecidas.

Cerisara (1999) aponta que as creches e pré-escolas não são as casas das crianças, nem hospitais e muito menos devem ser escolas de Ensino Fundamental. Mas a análise e debate das funções destas instituições permitiram constatar que esta dicotomização entre educar e cuidar das crianças deveria ser superada e progredir em direção a uma proposta menos discriminadora, em relação particularmente às crianças pobres.

No campo da Educação Infantil, cuidar está historicamente interligado à assistência e ao corpo. A partir de meados da década de 1980, os textos acadêmicos que se referiam a atividades assistenciais como "guarda", nesse momento histórico passou a ser substituída por expressões, como “ cuidado”, “cuidar”.

Segundo Kramer (2005):

Nos anos de 1990, com a perspectiva de as creches e pré-escolas serem incorporadas aos sistemas de ensino e passarem a ser consideradas a primeira etapa da educação básica, era preciso integrar as atividades de cuidado, realizadas nas creches, com as atividades de cunho mais pedagógico, desenvolvidas nas pré-escolas. A solução conceitual encontrada foi o binônimo educar e cuidar. Mas, se teve o mérito de assumir o corpo como objeto da educação, não resolveu as questões colocadas pela prática: ao contrário, tem provocado muita confusão! Entre outras coisas porque, no Brasil, os trabalhos de cuidar do corpo estavam relacionados no passado, às escravas e, atualmente, estão relacionados às mulheres das classes populares. (KRAMER, 2005, p. 68). 
Para esta autora, essa questão gerou muitos conflitos, uma vez que muitas professoras associam o ato de cuidar como algo doméstico, como uma desvalorização, como uma função que não necessitaria formação pedagógica e não seria responsabilidade de professores e sim de mulheres donas de casa.

Com isso, o trabalho docente na Educação Infantil foi compreendido por um longo tempo como algo similar a uma prática doméstica, que não demandava formação profissional, pois pressupunha funções de maternagem das crianças. Isso sem dúvida fortaleceu uma ideia social e cultural de que não havia diferenciação no trabalho da mulher no lar e na educação infantil, sendo este último desprovido de intencionalidade pedagógica e caracterizando-se como uma profissão que se constrói no feminino.

Para conseguirmos definir as/os profissionais que atuam com as crianças na Educação Infantil, devemos considerá-las/los em seu contexto social e cultural, incluindo também a existência de contradições sociais com as oposições de gênero, raça e idade. A definição da identidade destes/as profissionais muitas vezes não se constrói de forma claramente delineada, uma vez que ainda prevalece a ambiguidade das funções materna e docente (CERISARA, s.d).

Reconhece-se na atualidade que os/as professores/as de Educação Infantil devem trabalhar com ações de cuidado e educação, de forma indissociável, buscando concretizar uma pedagogia e parâmetros didáticos diferentes daqueles realizados nas escolas de Ensino Fundamental e até mesmo Ensino Médio.

Sem pretender uma definição acabada do perfil destas profissionais de educação infantil pode-se afirmar que elas têm sido mulheres, de diferentes classes sociais, de diferentes idades, de diferentes raças, com diferentes trajetórias pessoais e profissionais, com diferentes expectativas frente a sua vida pessoal e profissional (CERISARA, s.d, p.4).

Gomes (2003) também nos afirma que as profissões são construções dinâmicas, ou seja, elas se alteram ou deixam de existir através das transformações econômicas e pelo uso de novas tecnologias e exigências. A identidade profissional, esclarece a autora, é uma construção e é dinâmica, pois se produz entre a identidade interna ou "identidade de si", ou seja, a forma como cada um vai constituindo a sua imagem profissional e a imagem externa, que é a identidade para os outros.

Ongari e Molina (2003) fizeram uma pesquisa buscando conhecer as/os educadoras/res de creche e o processo de construção da identidade profissional e constataram que $65 \%$ das educadoras têm idade entre 30 a 39 anos, 75\% são casadas e 63\% têm filhos. Portanto, de acordo com estes estudos essas mulheres estão no momento central da fase adulta.

Também em pesquisa realizada, Micarello (2006) destaca a precariedade da formação de professores/as de Educação Infantil, considerando, também, que nos documentos oficiais relativos à Educação Infantil, há pouca clareza em relação ao seu perfil profissional.

Nono (s.d) em pesquisa realizada com professores/as, coordenadores/as, mães e pais de crianças entre 0 a 6 anos da comunidade, estas últimas não matriculadas na Educação Infantil, destacou a complexidade do processo de construção de identidade profissional docente em razão, sobretudo, da permanência das ideias sobre a ambiguidade do trabalho, visto ora como extensão daquele já realizado no lar, como cuidar da criança, e ora como 
educador/a, perdendo sua principal função que é incentivadora da aprendizagem e desenvolvimento da criança através da integração das práticas de educar e cuidar.

Este estudo decorre de uma pesquisa de iniciação científica e teve como questão de pesquisa: Quem são os/as profissionais* docentes das creches do Município de Descalvado/SP? O objetivo foi levantar e conhecer a trajetória profissional e características de um grupo de profissionais docentes de creches do município de Descalvado/SP, participantes de uma atividade de extensão de formação continuada intitulada: Formação de Professores de Educação Básica: uma parceria colaborativa entre escola e universidade. Justifica-se pela importância do conhecimento de um grupo de docentes em formação continuada, de modo a subsidiar as ações de formação, aproximando-as e desenvolvendo-as a partir da realidade de trajetória e características desses profissionais, o que contribuiu para a qualificação das ações de formação.

\section{Escolhas metodológicas}

Trata-se de uma pesquisa de abordagem qualitativa e que, segundo Ludke e André (1986), possui o ambiente natural como fonte de dados e o pesquisador como seu principal instrumento. Estas autoras apontam ainda que esse tipo de pesquisa propõe o contato direto do pesquisador com o pesquisado e com o ambiente que está sendo estudado através do trabalho de campo.

\footnotetext{
*No grupo colaborador deste estudo, contamos com a participação de professores/as, auxiliares e gestores de educação infantil, estes últimos com atuação em um período do dia em sala de educação infantil e outro na gestão escolar. Por atuarem diretamente com a criança apresentamos neste estudo este grupo como profissionais docentes (professores) de educação infantil.
}

Escolhemos nesta pesquisa o estudo de caso, pois trabalhamos com o conhecimento e a compreensão das características de um grupo de profissionais de uma dada realidade, atuantes em escolas de Educação Infantil (creches) do município de Descalvado/SP.

Utilizamos o questionário como instrumento de coleta de dados, contendo sete questões fechadas e uma questão aberta, construídas tomando como foco o objetivo da pesquisa. Todos os participantes foram esclarecidos sobre a pesquisa e concordaram com a participação, por meio da assinatura do Termo de Consentimento Livre e Esclarecido.

O questionário possuiu os seguintes temas de questões:

- Tempo de atuação no magistério e em outras atividades profissionais: indique em meses ou anos as alternativas que compreendem todas as suas experiências profissionais. Nesta questão, as alternativas (podendo ser assinaladas mais de uma) referiam-se à: atuação docente na creche, atuação docente na pré-escola, atuação docente no Ensino Fundamental, atuação como gestor (diretor, coord. pedagógico, etc.) na escola básica (Educação Infantil ou Ensino Fundamental), atuação em outra área profissional.

- Formação inicial - cursos: assinale as alternativas que fazem referência à(s) sua(s) formação(ões). Nesta questão as alternativas referiam-se a: magistério, pedagogia, especialização em Educação Infantil, especialização em outra área educacional (com espaço para descrição do curso realizado), outro curso superior, outro curso de Ensino Médio ou outra formação, 
sendo que as três últimas opções o/a participante descreveu a formação.

- Formação continuada: participou de cursos, programas, palestras e /ou outras propostas de formação continuada no campo da Educação Infantil ou na área educacional. Assinale os anos que participou e indique nas linhas abaixo quais foram. Nesta questão o/a participante teve como opções: em 2010; em 2009; em 2008; em 2007; em 2006; não participei nos últimos cinco anos; e espaço na questão para descrição de quais cursos ou processos formativos realizou.

- Situação familiar: nesta questão, o/a participante poderia escolher: casado; solteiro; divorciado/separado;viúvo; união estável. Filhos: com opção para indicar: sim; não; quantos e idade.

- Principais opções de lazer: assinale as alternativas que julgar pertinentes: leitura de livros, artigos e revistas; TV e internet; teatro;cinema; parques; outros (com espaço para indicação).

- Idade: menos de 20 anos; entre 20 e 30 anos; entre 31 e 40 anos; entre 41 e 50 anos; mais de 50 anos.

- Como questão aberta: relate os motivos que levaram à escolha pela profissão de professor(a) e à escolha pela atuação em creche.

Cabe dizer que, no questionário, havia um cabeçalho que pedia a indicação do gênero e atual campo e função(ões) de atuação na Creche Municipal de Descalvado/SP:

Participaram deste estudo 29 profissionais de Educação Infantil da rede municipal de ensino de Descalvado/ SP, que atuam em creches. Foram vinte e oito (28) professoras $^{*}$ e um (1) professor ${ }^{* *}$, com atuação na área da docência e na gestão escolar. Foram colocados nomes fictícios para cada uma das/dos profissionais colaboradoras/res que participaram deste estudo por meio do questionário aplicado e respondido. Os resultados encontrados serão apresentados e discutidos com base na análise de conteúdo e na literatura escolhida.

\section{Resultados e Discussão}

Na primeira pergunta do questionário, a saber: "Tempo de atuação no magistério e em outras atividades profissionais - indique em meses ou anos as alternativas que compreendem todas as suas experiências profissionais”, vinte e três (23) professoras/es responderam que possuem experiência anterior em docência, não necessariamente exclusiva na Educação Infantil. Além disso, as experiências na Educação Infantil englobam ainda auxiliar, monitor/a ou professor/a de creche ou na pré-escola.

Destas/es vinte e três (23) professoras/es doze (12) responderam que possuem experiência anterior de docência no Ensino Fundamental e Médio. Além disso, dessas/ es vinte e três (23) que estão na Educação Infantil, há três (03) professoras também possuem tempo de experiência de gestão escolar e uma (01) atuou também em outra área não mencionada.

Poucas/os são as/os profissionais sem percurso profissional anterior na Educação

\footnotetext{
*Tivemos a participação de professoras que também exerciam naquele momento a função de gestora escolar. Em razão disso, nos referimos neste estudo a estas profissionais como professoras.

** Tivemos a participação de um monitor de creche, que neste estudo será considerado como professor, por atuar diretamente em ações educativas com as crianças.
} 
Infantil, ou seja, 4 das/dos 29 no total, sendo que duas/dois trabalharam no Ensino Fundamental e apenas um tem experiência fora do contexto escolar, lembrando que a quarta professora atuou antes como auxiliar geral.

O grupo participante deste estudo tem percurso claro de trajetória profissional anterior na docência, ou seja, a sua profissão é o magistério e a docência. Vale ressaltar que das/os vinte e três (23) profissionais, dez (10) delas/es possuem experiência exclusiva de docência na Educação Infantil, e duas (02) não responderam a essa pergunta.

No caso deste grupo colaborador do estudo, cabe dizer que esse total de quase 1/3 de professores/professoras (10 no total) têm a oportunidade, no cotidiano de seu trabalho e também por meio do seu percurso profissional exclusivo na Educação Infantil, de construir sua identidade profissional, reafirmá-la em seu cotidiano e apoiar seus colegas de trabalho neste processo. A experiência de docência exclusiva na Educação Infantil é fundamental para a compreensão e a construção de saberes sobre a docência nesta etapa educativa, considerando as especificidades deste trabalho com bebês e crianças pequenas.

Em relação ao tempo de experiência exclusiva na Educação Infantil, temos uma (01) que possui apenas 5 meses de atuação nessa etapa educativa. Cabe dizer que os primeiros anos na profissão, de acordo com Nono (2011), são considerados como um período de aprendizagens, sendo importante para a permanência do professor na carreira como também para o tipo de profissional que será. Garcia (1999) considera o início da docência, como aquele pelo qual os professores precisam realizar a transição de estudantes a docentes, considerando esta etapa carregada de tensões, aprendizagens e, principalmente, insegurança.
Nono (2011) recorre a outros pesquisadores para esclarecer que, apesar das dificuldades encontradas principalmente no início da carreira, alguns professores/as, tentam permanecer de todas as formas nela e realizam um bom trabalho, e isso acontece pelo fato de estes/as profissionais gostarem de educar crianças, pela vontade de contribuir para o desenvolvimento da sociedade e por constatarem que esta profissão admite autonomia. No entanto, destaca a autora que muitos/as professores/as desanimam da profissão no início da carreira, pois

[...] é comum nas escolas pesquisadas à atribuição aos professores iniciantes de turmas de alunos consideradas por profissionais que atuam nas escolas como as mais difíceis, por possuírem alunos com grande variação nos níveis de aprendizagens e que, muitas vezes, não possuem materiais escolares mínimos e vêm de famílias caracterizadas pelo baixo poder aquisitivo - e/ ou, ainda, a atribuição de classes situadas nas zonas rurais, onde as condições de trabalho são piores do que nas escolas de zona urbana no que diz respeito à falta de material didático, pouca possibilidade de troca de experiência e acompanhamento pedagógico, delegação de turmas multisseriadas, dificuldade para se conciliar vida profissional e vida pessoal. O professor iniciante é "presenteado" com as piores turmas, os piores horários e as piores condições de trabalho, já que os professores experientes são os primeiros a escolherem suas aulas no momento de atribuição das classes (NONO, 2011, p 45).

No entanto, apesar das dificuldades, muitos acabam permanecendo na carreira por gosto pela profissão e, principalmente, pelo enfrentamento de acontecimentos que marcaram sua trajetória nas instituições onde trabalharam. 
Na referência de 05 a 10 anos de soma de tempo de experiência de docência na Educação Básica , temos quatro (4) profissionais: Claide com total de 5 anos, Leticia com total de 08 anos, Fátima, com total de 9 anos e Amanda, com total de 8 anos e 8 meses.

Na referência acima de 10 anos de tempo de experiência docente somando-se a Educação Infantil, o Ensino Fundamental e o Ensino Médio, temos seis (06) professoras/ res: Janaiana, com total de 27 anos; Mariana com total de 17 anos; Elena com total de 14 anos; Rute, com total de 18 anos; Julia com total de 13 anos de docência. Cabe dizer que essa professora também possui 3 anos de experiência na gestão escolar. A professora Andressa tem um total de 39 anos de docência, sendo 15 anos na pré-escola e 24 anos no Ensino Fundamental e Médio. Essa docente também possui 09 anos de experiência como gestora.

Tomando como referência a faixa de 5 a 10 anos de docência exclusiva na Educação Infantil, temos duas (02) professoras, sendo elas: Roberta (9 anos de docência) e Marlete (com 8 anos de docência). Na referência acima de 10 anos de docência exclusiva na Educação Infantil, temos oito (08) professoras: Roseli (com 18 anos de docência), Claudia (com 15 anos de docência), Fernanda (com 17 anos de docência), Carla (com 14 anos de docência), Giovana (com 20 anos de docência), Carol e Cristina (ambas com 16 anos de docência). Quanto à professora Silvia, essa tem 23 anos de docência na pré-escola e possui ainda 02 anos como gestora escolar.

Podemos perceber, a partir dos dados apontados, que a maioria das/dos profissionais podem ser considerados/as experientes, ou seja, possuem muitos anos de carreira no magistério, considerando os aspectos apontados por Huberman (1995). De acordo com Huberman (1995), há várias maneiras de estruturar o ciclo de vida dos/as professores/ professoras, afirmando que a carreira passa por uma série de "sequências".

Primeiramente, ele destaca as sequências ditas "de exploração" e de "estabilização”, que se verificam no começo de uma carreira.

\begin{abstract}
A exploração consiste em fazer uma opção provisória, em proceder a uma investigação dos contornos da profissão, experimentando um ou mais papéis. Se esta fase for globalmente positiva, passa-se a uma fase de "estabilização", ou de compromisso, na qual as pessoas centram a sua atenção no domínio das diversas características do trabalho, na procura de um setor de focalização ou de especialização, na aquisição de um caderno de encargos e de condições de trabalho satisfatórias e, em vários casos, na tentativa de desempenhar papéis e responsabilidades de maior importância ou prestígio, ou mais lucrativas. (HUBERMAN, 1995, p. 37).
\end{abstract}

Da fase da “exploração” ou das “opções provisórias” chega-se ao estágio de “comprometimento definitivo”, “ estabilização” e da “ tomada de responsabilidades”. A estabilização trata-se de comprometer-se definitivamente e da nomeação oficial, significando liberdade. E é a partir dessa fase que surgem as fases: experimentação e diversificação (HUBERMAN, 1995).

As pessoas lançam-se, então, numa pequena série de experiências pessoais, diversificando o material didático, os modos de avaliação, as formas de agrupar os alunos, as seqüências do programa, etc. Antes da estabilização, as incertezas, as inconseqüências e o insucesso geral tendiam de preferência a restringir qualquer tentativa de diversificar a gestão das aulas e a 
instaurar uma certa rigidez pedagógica. (HUBERMAN, 1995, p.41).

De acordo com o autor, o professor nesta fase de experimentação e diversificação busca novos estímulos, ideias, vontades, compromisso, ou seja, nesse momento, ele sente a necessidade de se comprometer. Porém, é nesta fase da diversificação que ocorre também uma ligeira sensação de rotina ou até mesmo uma crise existencial em relação à carreira.

O próximo período mencionado pelo autor é o da serenidade e distanciamento afetivo. No período da serenidade, as professoras possuem entre 45 e 55 anos de idade e nele elas começam a se lamentar, lembrando que quando eram jovens tinham mais energia e vontade. Porém, em contrapartida, evocam uma grande "seriedade", uma vez que se tornam mais experientes e, por isso, acabam prevendo tudo o que pode acontecer em sala de aula. Nesta fase, são menos sensíveis e vulneráveis, pois não acatam a avaliação dos outros, acreditando que as pessoas devem aceitar seu jeito de ser.

Depois da serenidade, há a fase do conservantismo e as lamentações, em que destacam-se professores/professoras entre 50-60 anos, sendo que a maioria queixa-se da evolução dos alunos, alegando que são menos disciplinados, menos motivados; queixam-se da política educacional, dos colegas mais jovens pela inexperiência, etc. $\mathrm{O}$ último período destacado é o desinvestimento. Nesta fase há o desinteresse de investir em si mesmos por se encontrarem no final da carreira, passando, assim, o “testemunho” aos jovens (HUBERMAN, 1995).

Na pergunta "Formação Inicial/Cursos - assinale as alternativas que fazem referência a sua formação”, podemos constatar que das 29 colaboradoras/colaboradores, 3 possuem formação apenas em Magistério, 5 possuem formação exclusiva de Pedagogia, 06 possuem formação em Magistério e Pedagogia, 02 possuem formação em Pedagogia e especialização em Educação Infantil, 01 fez Pedagogia, especialização em Educação Infantil e especialização em outra área, 01 possui formação em Magistério, outro curso superior e outro curso de Ensino Médio, 04 fizeram Pedagogia, Magistério, especialização em outra área e outro curso superior , 01 fez outro curso superior - Educação Física, 01 fez Magistério, Pedagogia e especialização em Educação Infantil e $01 \mathrm{fez}$ Magistério, Pedagogia e especialização em Gestão Escolar. Cabe dizer que do grupo de 29 colaboradoras/res, 15 profissionais possuem Pedagogia. Podemos perceber a partir desta questão que apenas 3 profissionais do total possuem apenas o Magistério e a maioria fez ou está cursando Pedagogia.

Outro resultado importante é que das 10 professoras com experiência exclusiva na Educação Infantil, 4 professoras já fizeram ou estão cursando Pedagogia. Apenas 1 docente dessas 10 colaboradoras não respondeu a essa questão, e em relação à formação única de Magistério, temos 2 professoras. Além disso, 2 professoras possuem curso de Magistério e Pedagogia e 1 tem Magistério e formação em licenciatura em Educação Física.

Das/os 04 profissionais que não possuem experiência anterior na Educação Infantil, 1 está cursando Pedagogia, 1 é formado em Educação Física, 1 fez Magistério, Pedagogia e especialização em Educação Infantil, e 1 fez Magistério, Pedagogia e especialização em Gestão Escolar .

As Diretrizes Curriculares Nacionais do Curso de Pedagogia (Resolução n. 01 de 2006) indicam que a formação do professor de eEducação Infantil deve acontecer no curso de Pedagogia, mas a Lei de Diretrizes e Bases da Educação Nacional - LDB 9394/96 
indica que o Ensino Médio como formação é permitido. Podemos constatar, através dos dados obtidos por meio destas questões, que a maioria das/dos entrevistadas/os é experiente e que uma parcela importante possui formação em Pedagogia.

Gatti e Barreto (2009) indicam, a partir de resultados de outras pesquisas e de dados do Censo Escolar da Educação Básica de 2006, que no Brasil a maioria dos professores possuía formação adequada quanto ao grau de escolaridade exigido para o nível de ensino em que atuava. Este dado é pertinente, considerando ainda que até 1996 a exigência por lei para atuar na docência da Educação Infantil e nos anos iniciais do Ensino Fundamental é a formação em nível médio (magistério). Estas autoras também nos apontam que particularmente, na Educação Infantil, 97,2\% das profissionais possuíam, em 2006, formação em nível médio ou mesmo superior .

Segundo Ongari e Molina (2003), na Itália, por exemplo, a formação das educadoras de creche ainda não se concretizou e muito menos é adequada, uma vez que os diplomas de profissionais desta área são muito heterogêneos, sendo alguns exclusivamente de orientação e assistencialista e outros cuja formação básica é equiparada à de professores de segundo e terceira infância. De acordo com uma pesquisa feita pelas autoras, 49\% têm um diploma com habilitação para profissões educativas ou assistencialistas para crianças maiores de três anos, enquanto 31\% têm um diploma específico para o trabalho educativo com crianças de 0 a 3 anos.

Na questão: “Formação continuada: participou de cursos, programas, palestras e/ou propostas de formação continuada no campo da Educação Infantil ou na área educacional. Assinale os anos em que participou e indique nas linhas abaixo quais foram ", das 29 entrevistadas/entrevistados, 21 assinalaram que participaram de cursos nos últimos 5 anos, 4 não participaram nos últimos 5 anos, 3 não responderam a essa questão e apenas 1 das entrevistadas/o não especificou o tempo, apenas os cursos que já fez. Podemos perceber, também, através das respostas, que a maioria fez os cursos Letra e Vida e o Pró-letramento.

Os cursos de formação continuada são essenciais para o aprofundamento de conhecimentos, pois de acordo com Gomes (2003) os cursos que formam professores de Educação Infantil são muito superficiais e distantes da prática, pois muitas vezes na formação inicial as disciplinas não direcionam suas discussões e conhecimentos teóricos e metodológicos para a docência com crianças de 0 a 3 anos.

Na pergunta “Situação familiar”, do total de 29 profissionais, 16 delas/es assinalaram que são casadas/os, 7 que são solteiras/os, 3 que são divorciadas/casadas/os, 2 que são viúvas/os, e uma (1) que possui união estável. Em relação aos filhos, 19 assinalaram que possuem filhos, e 10 que não possuem filhos.

Considerando apenas as/os profissionais que possuem experiência exclusiva de docência na Educação Infantil - creche e ou pré-escola (total de 10 profissionais), 6 profissionais responderam que são casadas, 2 são divorciadas, 1 profissional é solteira e 1 profissional é viúva. Sobre os filhos, 8 profissionais possuem filhos, e apenas 2 não possuem.

Na questão "Principais opções de lazer, assinale as alternativas que julgar pertinentes”, do total de 29 profissionais, várias relataram mais de uma alternativa, a saber: 24 preferem leitura de livros, artigos e revistas; 26 preferem TV e internet; 6 preferem cinema; 3 parques e 4 profissionais também responderam outras alternativas, como, por exemplo, brincar com o filho e curtir a família; reunião com amigos, viagens; e algumas não especificaram. Pode-se constatar, portanto, que a maioria das profissionais preferem 
ler livros, revistas, assistir TV e navegar na internet, como é o caso de Letícia e Fabiana, e que a única alternativa não assinalada foi o teatro.

Pode-se constatar que a maioria das/ dos entrevistadas/dos preferem TV e internet, ou seja, 26 delas/deles, sendo que 24 preferem leitura de livros, artigos e revistas, o que é muito bom, pois são caminhos de acesso às culturas, a conhecimentos gerais e, no caso de livros e artigos, podem ser da área educacional e especificamente do campo da docência na Educação Infantil. Neste quesito, 6 professoras/professores preferiram cinema, 3 parques e nenhuma/nenhum prefere teatro, o que mostra a falta de interesse ou falta de acesso a esse tipo de instrumento cultural.

Na pergunta sobre "Idade", das/os 29 profissionais que participaram do estudo, nenhuma/um assinalou que tem menos que 20 anos, 6 assinalaram que têm entre 20 e 30 anos, 11 têm entre 31 e 40 anos, 8 têm entre 41 e 50 anos e apenas 4 das entrevistas/os têm mais de 50 anos, o que mostra que o grupo é constituído de profissionais em idade adulta, não tão jovens.

Das/os profissionais com experiência exclusiva na Educação Infantil (total de 10 profissionais), 3 possuem mais de 50 anos (Regiane, Fernanda e Carla), 6 possuem de 31 anos a 40 anos (Roberta, Marlete, Roseli, Claudia e Cristina, Giovana) e 1 possui idade na faixa de 41 a 50 anos (Carol).

Das/os profissionais com experiência na docência da Educação Infantil e anos iniciais do Ensino Fundamental (no total 13 profissionais), 4 possuem entre 41 e 50 anos (Amanda, Rute, Silvia e Andressa), 5 possuem entre 31 e 40 anos (Bruna, Letícia, Janaina, Mariana e Julia) e 4 possuem entre 20 e 30 anos (Marta, Cleide, Fátima e a Elena).

Na pergunta "Relate os motivos que levaram à escolha pela profissão de professor/a e à escolha pela atuação em creche”, as respostas descritas mostraram que, das 29 professoras, 10 docentes (Cristina, Carla, Marlete, Carol, Leticia, Mariana, Silvia, Lucia, Fabiana e Marina) responderam que escolheram por necessidade de trabalhar, falta de oportunidade ou por única opção.

“Inicialmente fiz o magistério por falta de
opção, fui trabalhar como professora mui-
tos anos após; gostei muito, fiz o curso de
pedagogia, continuei trabalhando, passei
para a coordenação. Fui fazer pós em ges-
tão escolar e atualmente trabalho como
gestora em uma creche há 3 anos na atual
administração” (Marina)

"As coisas foram acontecendo, precisando trabalhar, fui parar em uma creche, em 1997, onde estou até hoje como educadora” (Carla)

\begin{abstract}
"Quando iniciei meu trabalho na creche (16 anos atrás) eu era muito nova e foi por uma oportunidade de emprego. Logo, em seguida, gostei muito do trabalho e da profissão. Continuo sendo monitora de creche e hoje em dia, curso Pedagogia para no futuro poder ser 'professora' pois gosto muito de trabalhar com as crianças, querendo me aperfeiçoar para continuar em creche como professora” (Cristina).
\end{abstract}

De acordo com Gomes (2009), nos dias atuais, é quase impossível afirmar que existe a possibilidade de haver "escolha” profissional para a maioria da população brasileira, principalmente para os mais pobres, ou seja, a maior parte opta por uma profissão de nível médio, que possibilita a entrada no mercado de trabalho, além de complementar a renda familiar e concluir a escolarização básica. Como é o caso de uma das colaboradoras da pesquisa feita por Gomes (2009): 
Fui fazer contabilidade, pois era o que estava mais próximo das minhas possibilidades. Quando estava terminando o curso, percebi que não tinha nada a ver comigo. Na mesma escola tinha o curso de extensão de Magistério, era só fazer algumas adaptações de matérias, então eu fiz e gostei do Magistério. E me encontrei mais ainda quando estava fazendo o estágio na pré-escola. Aí eu já me defini mesmo. Nessa época eu trabalha em uma empresa da região, na área da produção, das seis horas da manhã às quatorze horas e estava noiva já para casar. Depois fiz Pedagogia e já ingressei na Prefeitura Municipal como professora. Naquela época não tinha concurso público, me lembro de ter feito uma prova e depois ter sido indicada para trabalhar ( MONICA apud GOMES, 2009, p. 130).

Doze profissionais responderam que escolheram porque gostam de crianças, de atuar na Educação Infantil ou por gostar de docência:

“ Desde pequena sempre quis ser professora e a escolha por creche é que durante 10 anos fui professora da educação infantil e fui concebida pela secretaria da educação ser diretora. Adoro a educação, adoro crianças pequenas. Meu sonho seria fazer mestrado ou doutorado nesta área. Quando ouço vocês falarem que trabalham na universidade, fico imaginando o quanto deve ser gratificante e maravilhoso o trabalho na área de pesquisa na educação infantil” (Andressa).

“Inicialmente optei pelo magistério por influência dos meus pais e encarava a profissão como temporária. Porém, após o contato com a sala de aula, me apaixonei pela docência e decidi continuar os estudos na área da educação, cursando Letras na UFSCar. Ingressei na creche em 2009 como diretora com convite da Secretaria Municipal de Educação” (Julia).

“A escolha por monitora de creche, pri-
meiramente por gostar muito de criança e
pela vontade de ajudar a melhorar a educa-
ção em nosso país, posteriormente com a
oportunidade de dar continuidade aos meus
estudos nesta área” (Marisa).

"Sou professora porque ensinar e acho muito gratificante e enriquecedor o trabalho com as crianças” (Cleide).

Três participantes responderam que os motivos foram as professoras de infância ( 2 participantes porque a sua professora foi um exemplo, e outro, porque foi péssima):

"O motivo pelo qual escolhi essa profissão foi por uma grande gratidão e amor a uma professora que tive na infância. Ela é fantástica e muito dedicada e devido sua atenção, carinho e amor a profissão fez com que eu me apaixonasse pela profissão” (Bruna)

“ Por causa da minha prima, pois ela é professora, e eu sempre a admirei”. (Giovana).

“ Bom, escolhi ser professor de educação física, pois tive péssimos professores desta área, e era uma área que tinha muita afinidade. Quando comecei o curso, abriu concurso para monitor de creche e resolvi prestar, pois gostava de crianças, fui chamado recentemente e apesar de sofrer um pouco no começo acabei gostando do que faço”. (Pedro)

Duas docentes responderam que escolheram por outras situações:

"Este é o primeiro ano e estou por remoção” (Roseli) 
"Porque preferi um ensino segundo grau profissionalizante, ingressei logo quando conclui e passei a ter afinidade com a área e a dar continuidade aos estudos na mesma área. Fui para a creche, pois precisava do período da manhã” (Janaina).

Cabe dizer que apenas um/a profissional não respondeu a essa pergunta.

Pode-se perceber, também, através da pesquisa de Gomes (2009) e do questionário aplicado aos profissionais docentes das creches de Descalvado que, além da necessidade de trabalhar, elas/eles escolheram a profissão por influência, por gostar de crianças, por afinidade, pelo desejo pela docência, etc. Neste caminho do trabalho cotidiano com as crianças e seus pares, vários profissionais foram apreendendo o gosto pela profissão. Nono (2011) esclarece que as professoras apresentam fragilidades na formação inicial que precisam ser superadas no decorrer de seu trabalho com as crianças, e estas fragilidades são intensas em pautas como o domínio de conteúdos específicos de diferentes naturezas, falta de domínio da tecnologia, etc. Essas dificuldades são superadas à medida que se inserem na prática profissional e se atualizam nos cursos de formação continuada.

\section{Considerações transitórias}

A maioria das/dos profissionais que atuam nas creches municipais de Descalvado/ SP são mulheres e possui experiência docente anterior na Educação Infantil. No caso do grupo em questão, a maioria destes profissionais possui formação em Pedagogia. Isso é um aspecto importante considerando a realidade de outros municípios, em que a formação é em nível médio ou mesmo uma ausência de conclusão de cursos de formação por parte das/ os professoras/res que atuam com crianças de 0a 3 anos, em creches públicas.

No entanto, mesmo com formação em nível superior, em curso de Pedagogia, sabemos, por meio de pesquisa desenvolvida por Gatti e Barreto (2009), que há uma ausência de formação específica para a docência em Educação Infantil demonstrada pelas análises realizadas nos currículos dos cursos de Pedagogia. Gomes (2003) também destaca esta problemática da formação inicial, quando aponta que há cursos muitos superficiais e distantes da prática que formam professores/as da Educação Infantil em nível médio e superior, além de uma ausência de conhecimentos teóricos e metodológicos sobre os processos de ensino e aprendizagem e desenvolvimento de crianças de 0 a 3 anos.

\section{Referências}

BRASIL. Diretrizes Curriculares Nacionais do Curso de Pedagogia. Resolução n. 01, maio. Brasília, República Federativa, 2006.

Lei de Diretrizes e Bases da Educação Nacional, n. 9394. Brasília, República Federativa do Brasil, 1996.

CERISARA, A.B. Em busca da identidade das profissionais de educação infantil. s.d. Disponível em : www.educacao.salvador. ba.gov.br. Acesso em: maio de 2013.

Educar e cuidar: por onde anda a educação infantil? Perspectiva. Florianópolis, v.17, n. Especial, p.11-21, Jul./dez.1999.

GARCIA, C. M. Formação de professores: para uma mudança educativa. Porto: Portugal, 1999. 
GATTI, B. A.; BARRETTO, E. S. de S. Professores do Brasil: impasses e desafios. Brasília: Unesco, 2009.

GOMES, M. de O. As identidades de educadoras de crianças pequenas: um caminho do “eu” ao nós. 2003. Tese (Doutorado em Educação). Faculdade de Educação, Universidade de São Paulo, São Paulo.

Formação de professores na educação infantil. São Paulo: Cortez, 2009.

HUBERMAN, M. O ciclo de vida profissional dos professores. In: NÓVOA, A. Vidas de professores. $2^{\text {a }}$ ed. Portugal, 1995, p.31-61.

KRAMER, S. Profissionais de educação infantil: gestão e formação. São Paulo: Cortez, 2005.

KUHLMANN JUNIOR, M. Infância e educação infantil: uma abordagem histórica. Porto Alegre: Mediação, 1998.

LUDKE, M.; ANDRE, M. E. D. A. Pesquisa em educação: abordagens qualitativas. São Paulo: EPU, 1986.

MARQUEZ, C. G. O Banco Mundial e a educação infantil no Brasil. 2006. Dissertação. (Mestrado em Educação). Faculdade de Educação, Universidade Federal de Goiás, Goiania.

MICARELLO, H. A. L. S. Professores da pré-escola: trabalho, saberes e processos de construção. 2006. Tese (Doutorado em Educação). Pontifícia Universidade Católica, Rio de Janeiro.

NONO, M. A. Identidade do professor de educação infantil. In: NONO, M. A. Fundamentos e princípios da educação infantil. Livro Didático- Univesp. s.d. Disponível em : www. acervodigital.unesp. com.br. Acesso em : 04 de abril de 2013.
Professores iniciantes: o papel da escola em sua formação. Porto Alegre: Mediação, 2011.

ONGARI, B. MOLINA, P. A educadora de creche: construindo suas identidades. São Paulo: Cortez. 2003. 